\title{
El liberalismo internacional y la vigencia de la democracia
}

\begin{abstract}
WiLliam-Guillermo JimÉNEZ*
* Posdoctor en Derecho. Titular de la Escuela Superior de Administración Pública y Universidad La Gran Colombia, miembro de los grupos de investigación Política, Derecho y Gestión Pública (ESAP) y Teoría del Derecho, de la Justicia y de la Política (UGC), willjime@ esap.edu.co, william.jimenez@ugc.edu.co, calle 44 No. 53-37 Bogotá, Colombia.
\end{abstract}

Meneses, O. (2020) Editorial. Inciso, 22(2) sp

DOI: http://dx.doi.org/10.18634/incj.22v.2i.1041

L

a teoría política del liberalismo sintetizó en la doctrina más de cuatro siglos de práctica a través de la cual las llamadas profesiones liberales asociadas a la mentalidad burguesa -según el famoso ensayo de José Luis Romero-, habían transformado el mundo. Sin embargo, esta teoría tan variada y vistosa como el mundo que describe, goza de una legión de admiradores solo comparable a la de sus detractores. Así, por un lado, son ampliamente reconocidos sus aportes en el desarrollo de los derechos humanos, el pensamiento crítico-científico, el desarrollo económico y la cooperación institucional, así como en la promoción de una cultura política democrática antiabsolutista y una sociedad civil organizada; mientras que por el otro, se le ha hecho responsable por algunas de las crisis más serias en materia de política económica, pobreza y desigualdad promovidas por algunas de las agencias multilaterales calificadas por ello como 'neoliberales'. Sus análisis sobre las relaciones entre libertad pública y privada o entre intervención y desregulación, por ejemplo, han contribuido asertivamente al desarrollo de la teoría política general.

Con este trasfondo, Meneses ${ }^{1}$ presenta de forma sistemática los elementos centrales de la teoría a partir de aquellas obras relevantes de Immanuel Kant y Hans Kelsen que dieron lugar a los desarrollos complementarios en la escuela de pensamiento denominada liberalismo internacionalista, entre los que sobresalen los trabajos de Norberto Bobbio, Luigi Ferrajoli y Robert Keohane, pues desde estos en donde sucesos como las atrocidades ocurridas durante la Segunda Guerra Mundial, expuestas en los juicios de Nurembeg y Tokio, datan de los antecedentes del concierto internacional por los derechos humanos y de los tribunales consecuentes.

Así, tras la terrible experiencia de las guerras mundiales, el liberalismo del siglo XX resulta rescatado y relanzado en varios documentos que sirvieron como preparación institucional de

1. Meneses Quintana Orlando, Derecho y política en la posmodernidad: teoría liberal de la justicia, Ediciones Universidad La Gran Colombia, Bogotá. 2018 
cara a la reconstrucción (Plan Marshall), en sus fases de cooperación política, económica y de infraestructura traducida en los procesos de constitucionalización del derecho. Norberto Bobbio, que había sido encarcelado por el régimen fascista debido a la expresión de sus ideas liberales, después de la guerra piensa radicalmente la democracia de masas rescatando la naturaleza y función de la democracia institucional, al tiempo que señala hacia una fundamentación filosófico-política de las Naciones Unidas teniendo en cuenta su difícil desarrollo a partir de la experiencia de la Sociedad de Naciones y los desafíos de la Guerra Fría.

Luigi Ferrajoli, discípulo de Bobbio y autor de esa obra monumental que es Principia luris, a finales de la década de 1960 como magistrado había llevado a la práctica su ideario liberal en el movimiento denominado Magistratura Democrática, en el que defendía el activismo judicial a favor de la garantía de los derechos fundamentales; respecto a la ONU, en varias oportunidades condenada a la inacción por el Consejo de Seguridad, piensa que solo puede salvarla la conciencia internacional sobre sus características y aportes, que ninguna otra organización estatal o no-gubernamental pueden suplir.

El liberalismo internacionalista -crítico del realismo hegemónico-, hace énfasis en la capacidad de colaboración de los Estados: John Rawls, que en su contexto norteamericano había sido considerado por unos como insuficientemente igualitario y por otros como insuficientemente liberal, publica hacia el final de su vida El derecho de los pueblos, en el que presenta su ideal (como "utopía realista") de una comunidad de naciones o sociedad de los pueblos inspirado en el kantiano foedus pacificum o el kelseniano civitas maxima a manera de comunidad jurídica. Por su parte, Robert Keohane, el más crítico frente al realismo político, postula la independencia relativa del orden internacional que se desenvuelve con su propia lógica; sus investigaciones detallan este escenario parcialmente autónomo en interacción con los intereses de los Estados y de actores no estatales (ONG, corporaciones, instituciones internacionales) que ejercen una influencia creciente, y en el que la cooperación se encuentra orientada por expectativas mutuas asociadas a la institucionalización de intereses y también de valores.

El liberalismo constituye así una tradición de pensamiento moderno que muestra, por un lado, los límites del expansionismo grosero que dispara primero y pregunta después; y por el otro, la capacidad de cooperación institucional y la geopolítica de colaboración estratégica que incorpora nuevos actores relevantes como las economías emergentes. El liberalismo comercial bajo las condiciones y el diseño institucional correctos puede facilitar la conjunción de esfuerzos de la mano de un liberalismo regulatorio con énfasis en el impacto de las leyes y formas institucionalizadas de proceder, generando confianza en el tipo de intercambio asociado al laissez-faire. 